\title{
Was There Shortening of the Interval Between Diagnosis and Treatment of Colorectal Cancer in Southern Netherlands Between 2005 and 2008?
}

\author{
L. N. van Steenbergen - V. E. P. P. Lemmens • \\ H. J. T. Rutten · H. Martijn · J. W. W. Coebergh
}

Published online: 25 February 2010

(c) The Author(s) 2010. This article is published with open access at Springerlink.com

\begin{abstract}
Background The Dutch Cancer Society proposed that the interval between diagnosis and start of treatment should be less than 15 working days. The purpose of this study was to determine whether the interval from diagnosis to treatment for patients with colorectal cancer (CRC) shortened between 2005 and 2008 in hospitals in southern Netherlands.

Methods Patients with CRC diagnosed in six hospitals in southern Netherlands during January to December in 2005 $(n=445)$ and January to July in $2008(n=353)$ were included. The time between diagnosis and start of treatment was assessed, and the proportion of patients treated within the recommended time ( $<15$ working days) was calculated. Results The time to treatment for colon cancer patients was 13 working days in 2005 and 17 working days in 2008. For rectal cancer patients, the median time to preoperative radiotherapy was 28 working days in 2005 and 30 working days in 2008, and the median time to surgical treatment for rectal cancer patients was 26 working days in 2005 and 18 working
\end{abstract}

L. N. van Steenbergen $(\bowtie)$. V. E. P. P. Lemmens .

J. W. W. Coebergh

Eindhoven Cancer Registry, Comprehensive Cancer Centre

South, PO Box 231, 5600 AE Eindhoven, The Netherlands

e-mail: research@ikz.nl

V. E. P. P. Lemmens - J. W. W. Coebergh

Department of Public Health, Erasmus University Medical

Centre, Rotterdam, The Netherlands

H. J. T. Rutten

Department of Surgery, Catharina Hospital Eindhoven,

Eindhoven, The Netherlands

H. Martijn

Department of Radiotherapy, Catharina Hospital Eindhoven,

Eindhoven, The Netherlands days in 2008. Time to treatment did not shorten between 2005 and 2008 for colon and rectal cancer patients, except for rectal cancer patients who underwent surgery as initial treatment in patients aged $>70$ years and those with stage I disease. Substantial variation was seen among hospitals.

Conclusions Time to treatment for patients with CRC in southern Netherlands did not shorten between 2005 and 2008. The time to treatment should be reduced to meet the advice of the Dutch Cancer Society.

\section{Introduction}

Colorectal cancer (CRC) is the third most frequent cancer in The Netherlands, with more than 11,000 new cases annually and a lifetime risk of more than 5\% [1]. Over a period of more than two decades, a clear improvement in survival of patients with CRC was attained by earlier detection due to a lower barrier for endoscopy, better staging, improved surgery, and combined-modality treatment [2, 3]. Most of these patients still present with symptomatic disease because population-based screening has not yet been implemented in The Netherlands.

Since 2000, guidelines in Dutch specialized care (Treeknormen) indicate that the time from diagnosis to the start of clinical treatment should be within 35 days for $80 \%$ of patients and within 49 days for all patients [4]. For patients with life-threatening disease including cancer, a Dutch Cancer Society working group (consisting of medical specialists, social medicine specialists, and an economist) proposed in 2005 that the interval between diagnosis and treatment of cancer should be less than 15 working days [5], more or less in agreement with several other countries, including Denmark and the United Kingdom [6, 7]. To decrease the interval between diagnosis and treatment a 
project called Sneller Beter (Getting Well Faster) was started in November 2003 in The Netherlands funded by the Ministry of Health [8].

It is arbitrary to what degree treatment delay contributes to disease stage at presentation [9]. However, a longer time interval from diagnosis to treatment might have a negative effect on the patient's psychological well-being [10, 11], which may affect the physical condition of the patient. Symptoms or clusters of symptoms might affect the interval between diagnosis and treatment as symptoms are related to the severity of the disease [12].

The purpose of this study was to determine whether the time from diagnosis to treatment for patients with CRC shortened between 2005 and 2008 in hospitals in southern Netherlands.

\section{Methods}

\section{Data collection}

Population-based data from the Eindhoven Cancer Registry (ECR), which is maintained by the Comprehensive Cancer Centre South, were used. The ECR collects data for all patients newly diagnosed with cancer in the southern part of The Netherlands. The ECR serves 10 community hospitals, 6 pathology departments, and 2 radiotherapy institutes in an area comprising 2.3 million inhabitants. Information on diagnosis, staging, and treatment is obtained routinely from the medical records [13]. In addition, information on comorbidity has been collected since 1993 based on the Charlson Co-morbidity Index [14]. Socioeconomic status, based on individuals' fiscal data on the economic value of the home and household income, is provided at an aggregated level for each postal code [15]. The quality of the data is high because of thorough training of the registrars and computerized consistency checks at regional and national levels. Completeness is estimated to be at least 95\% [16].

\section{Study population}

For the present study, 445 patients with primary CRC diagnosed in 2005 and 353 patients with primary CRC diagnosed between January 1, 2008 and August 1, 2008 in six hospitals in southern Netherlands were included. All patients underwent resection of their tumor or radiotherapy treatment within 6 months after diagnosis. Patients with previous cancer ( $n=137$ ) or who underwent acute resection $(n=34)$ were excluded. Colon cancer was defined as C18, rectal cancer as C19-C20 according to the International Classification of Diseases for Oncology 03 [17]. Tumor localization was categorized into anatomic subsites: proximal colon, consisting of the cecum, appendix, ascending colon, hepatic flexure, transverse colon, and splenic flexure (C18.0-C18.5); distal colon, consisting of descending colon and sigmoid (C18.6-C18.7); colon not otherwise specified (NOS) (C18.8, C18.9); and rectum, consisting of rectosigmoid and rectum (C19.9, C20.9).

The TNM stage was based on the pathological stage and the clinical stage when the pathological stage was unknown, as clinical stage alone was unknown for many patients. Date of diagnosis was defined as the date of histological verification of the tumor. Time to treatment was defined as the time interval between the histologically confirmed diagnosis and the start of initial treatment, which is surgical resection, except for those undergoing preoperative radiotherapy. Nonelective surgical treatment was defined as surgery and diagnosis on the same day. The starting date of radiotherapy was obtained from both radiotherapy institutes in the ECR region.

Additional data were extracted from the medical records by one of the authors (L.N.S) and a research assistant, under supervision of the treating physicians. This included date of imaging procedures and date of surgery. Imaging procedures included thoracic radiography, abdominal ultrasonography (US), abdominal computed tomography (CT), and magnetic resonance imaging (MRI). For patients diagnosed in 2005, symptoms were registered based on the medical record, with a maximum of four symptoms per patient. An early-stage cluster was created that contained patients who had rectal blood loss, mucus in stool, or no complaints. Data about radiotherapy including starting date of treatment and date of registration at the institute were obtained from the radiotherapy institutes.

\section{Statistical analysis}

Time between the diagnosis of CRC and imaging procedures, surgery, and radiotherapy was assessed. Variation in time between diagnosis and treatment was determined per age group ( $<70$ years and $\geq 70$ years), stage, socioeconomic status, co-morbidity, and hospital. The MannWhitney test was conducted to test whether the time between diagnosis and treatment differed markedly between predefined groups of patients. Furthermore, the time between diagnosis and treatment was described for symptoms. The proportion of patients who were treated within the time recommended by the Dutch Cancer Society advice were compared between 2005 and 2008.

Survival time was defined as the time from diagnosis to death or January 1, 2009 for the patients who were still alive. A crude 5-year survival rate was calculated, and a log-rank test was carried out to compare survival proportions. A multivariable proportional hazards regression analysis was used to discriminate independent risk factors for death (SAS system 9.1; SAS Institute, Cary, NC, USA). A value of $p<0.05$ was considered statistically significant. 


\section{Results}

Colon cancer patients diagnosed in 2005 and 2008 were similar in age, socioeconomic status, co-morbidity, stage, and timing of surgical treatment. However, those diagnosed in 2008 more often had a tumor located in the distal colon, and the pathologic lymph node status differed. The mean age of patients with colon cancer was 71 years (range 36-91 years), and almost half them suffered from one or more co-morbid conditions. Most of the patients had a T3 tumor, and $16 \%$ of those diagnosed in 2005 and $11 \%$ diagnosed in 2008 had metastatic disease at diagnosis (Table 1). Most of the rectal cancer patients underwent preoperative radiotherapy. In 2005 the age of rectal cancer
Table 1 Descriptives of the study population: colon cancer $^{a}$
NOS Not otherwise specified

a No patients with previous cancer

b Excluding hypertension, as it is generally a minor co-morbidity

${ }^{c}$ If the pathologic stage was unknown, the clinical stage was used

${ }^{\mathrm{d}}$ Nonelective was defined as surgery on the same day as the diagnosis

$* p<0.05$ between 2005 and 2008; ** $p<0.0001$ between 2005 and 2008

\begin{tabular}{|c|c|c|c|c|}
\hline \multirow[t]{2}{*}{ Parameter } & \multicolumn{2}{|c|}{$2005(n=177)$} & \multicolumn{2}{|c|}{$2008(n=219)$} \\
\hline & No. & $\%$ & No. & $\%$ \\
\hline Age (years), mean and range & $70(72-89)$ & & $71(38-94)$ & \\
\hline Sex (male) & 92 & 52 & 110 & 50 \\
\hline \multicolumn{5}{|l|}{ Socioeconomic status } \\
\hline Low & 42 & 24 & 50 & 23 \\
\hline Intermediate & 61 & 35 & 84 & 38 \\
\hline High & 64 & 36 & 68 & 31 \\
\hline Institutionalized & 7 & 4 & 8 & 4 \\
\hline Unknown & 3 & 2 & 9 & 4 \\
\hline \multicolumn{5}{|l|}{ Co-morbidity ${ }^{\mathrm{b}}$} \\
\hline None & 72 & 41 & 106 & 48 \\
\hline One & 51 & 29 & 49 & 22 \\
\hline Two or more & 42 & 24 & 55 & 25 \\
\hline Unknown & 12 & 7 & 9 & 4 \\
\hline \multicolumn{5}{|l|}{ Tumor site } \\
\hline Proximal colon & 122 & 69 & 122 & $56 * *$ \\
\hline Distal colon & 52 & 29 & 96 & 43 \\
\hline Colon (other/NOS) & 3 & 2 & 1 & 1 \\
\hline \multicolumn{5}{|l|}{ Pathological T stage ${ }^{\mathrm{c}}$} \\
\hline 1 & 9 & 5 & 17 & 8 \\
\hline 2 & 24 & 14 & 32 & 15 \\
\hline 3 & 115 & 65 & 132 & 60 \\
\hline 4 & 27 & 15 & 29 & 13 \\
\hline Unknown & 2 & 1 & 9 & 4 \\
\hline \multicolumn{5}{|l|}{ Pathologic N stage } \\
\hline No & 103 & 58 & 113 & $52 *$ \\
\hline $\mathrm{N}+$ & 70 & 40 & 90 & 41 \\
\hline Unknown & 4 & 2 & 16 & 7 \\
\hline \multicolumn{5}{|l|}{ M stage } \\
\hline 0 & 126 & 71 & 172 & 79 \\
\hline 1 & 29 & 16 & 24 & 11 \\
\hline Unknown & 22 & 12 & 23 & 11 \\
\hline TNM stage & 29 & 16 & 39 & 18 \\
\hline \multicolumn{5}{|l|}{ I } \\
\hline II & 66 & 37 & 77 & 35 \\
\hline III & 51 & 29 & 72 & 33 \\
\hline IV & 29 & 16 & 24 & 11 \\
\hline Unknown & 2 & 1 & 7 & 3 \\
\hline \multicolumn{5}{|l|}{ Timing of surgical treatment } \\
\hline Elective & 128 & 72 & 157 & 72 \\
\hline Nonelective $^{\mathrm{d}}$ & 49 & 28 & 62 & 28 \\
\hline
\end{tabular}


patients who did and those who did not undergo preoperative radiotherapy was similar, whereas in 2008 those who underwent preoperative radiotherapy were younger (65 vs. 74 years). In 2008 almost none who underwent radiotherapy had a tumor in the rectosigmoid, whereas $8 \%$ did so in
2005. Socioeconomic status, co-morbidity, and stage were similar for rectal cancer patients between 2005 and 2008 (Table 2).

For patients with colon cancer the median time to treatment was 13 working days in 2005 and 17 working
Table 2 Descriptives of the study population: rectal cancer $^{\mathrm{a}}$
PreopRT Preoperative

radiotherapy

${ }^{a}$ No patients with previous cancer

b Excluding hypertension, as it is generally a minor comorbidity

${ }^{c}$ If the pathologic stage was unknown, the clinical stage was used

${ }^{d}$ Nonelective was defined as surgery on the same day as the diagnosis

$* p<0.05$ between 2005 and 2005 ; ** $p<0.0001$ between 2005 and 2008

\begin{tabular}{|c|c|c|c|c|c|c|c|c|}
\hline \multirow[t]{3}{*}{ Parameter } & \multicolumn{4}{|c|}{$2005(n=186)$} & \multicolumn{4}{|c|}{$2008(n=134)$} \\
\hline & \multicolumn{2}{|c|}{$\begin{array}{l}\text { No preop RT } \\
(n=46)\end{array}$} & \multicolumn{2}{|l|}{$\begin{array}{l}\text { Preop RT } \\
(n=140)\end{array}$} & \multicolumn{2}{|l|}{$\begin{array}{l}\text { No preop RT } \\
(n=27)\end{array}$} & \multicolumn{2}{|l|}{$\begin{array}{l}\text { PreopRT } \\
(n=107)\end{array}$} \\
\hline & No. & $\%$ & No. & $\%$ & No. & $\%$ & No. & $\%$ \\
\hline $\begin{array}{l}\text { Age (years), mean } \\
\text { and range }\end{array}$ & $69(36-85)$ & & $68(33-90)$ & & $74(58-94) *$ & & $65(31-93)$ & \\
\hline Sex (male) & 23 & 50 & 76 & 55 & 21 & $78 *$ & 63 & 59 \\
\hline \multicolumn{9}{|c|}{ Socioeconomic status } \\
\hline Low & 8 & 17 & 27 & 19 & 6 & 22 & 22 & 20 \\
\hline Intermediate & 12 & 26 & 59 & 42 & 6 & 22 & 49 & 46 \\
\hline High & 20 & 43 & 45 & 32 & 11 & 41 & 34 & 32 \\
\hline Institutionalized & 5 & 11 & 7 & 5 & 2 & 7 & 1 & 1 \\
\hline Unknown & 1 & 2 & 2 & 1 & 2 & 7 & 1 & 1 \\
\hline \multicolumn{9}{|l|}{ Co-morbidity ${ }^{\mathrm{b}}$} \\
\hline None & 27 & 59 & 65 & 46 & 12 & 44 & 57 & 53 \\
\hline One & 12 & 26 & 40 & 29 & 8 & 30 & 24 & 22 \\
\hline Two or more & 6 & 13 & 24 & 17 & 7 & 26 & 22 & 21 \\
\hline Unknown & 1 & 2 & 11 & 8 & 0 & 0 & 4 & 4 \\
\hline \multicolumn{9}{|l|}{ Tumor site } \\
\hline Rectosigmoid & 19 & 41 & 11 & 8 & 6 & $22 * *$ & 2 & $2 * *$ \\
\hline Rectum & 27 & 59 & 129 & 92 & 21 & 78 & 105 & 98 \\
\hline \multicolumn{9}{|l|}{ Pathologic T stage ${ }^{c}$} \\
\hline 1 & 5 & 11 & 4 & 3 & 5 & 19 & 5 & 5 \\
\hline 2 & 14 & 30 & 46 & 33 & 8 & 30 & 32 & 30 \\
\hline 3 & 25 & 54 & 73 & 52 & 14 & 52 & 50 & 47 \\
\hline 4 & 2 & 4 & 10 & 7 & 0 & 0 & 8 & 7 \\
\hline Unknown & 0 & 0 & 7 & 5 & 0 & 0 & 12 & 11 \\
\hline \multicolumn{9}{|l|}{ Pathologic N stage } \\
\hline NO & 21 & 46 & 88 & 63 & 12 & 44 & 62 & 58 \\
\hline $\mathrm{N}+$ & 20 & 43 & 45 & 32 & 9 & 33 & 31 & 29 \\
\hline Unknown & 5 & 11 & 7 & 5 & 6 & 22 & 14 & 13 \\
\hline \multicolumn{9}{|l|}{ M stage } \\
\hline 0 & 33 & 72 & 106 & 76 & 22 & 81 & 84 & 79 \\
\hline 1 & 7 & 15 & 22 & 16 & 5 & 19 & 11 & 10 \\
\hline Unknown & 6 & 13 & 12 & 8 & 0 & 0 & 12 & 11 \\
\hline \multicolumn{9}{|l|}{ TNM stage } \\
\hline I & 15 & 33 & 42 & 30 & 12 & 44 & 27 & 25 \\
\hline II & 10 & 22 & 37 & 26 & 6 & 22 & 32 & 30 \\
\hline III & 14 & 30 & 35 & 25 & 9 & 33 & 28 & 26 \\
\hline IV & 7 & 15 & 22 & 16 & 0 & 0 & 11 & 10 \\
\hline Unknown & 0 & 0 & 4 & 3 & 0 & 0 & 9 & 8 \\
\hline \multicolumn{9}{|c|}{ Timing of surgical treatment } \\
\hline Elective & 43 & 93 & 140 & 100 & 18 & $67 *$ & 107 & 100 \\
\hline Nonelective $^{\mathrm{d}}$ & 3 & 7 & 0 & 0 & 9 & 33 & 0 & 0 \\
\hline
\end{tabular}


Fig. 1 a Time from diagnosis to start of treatment for colon cancer patients. b Time from diagnosis to start of treatment for rectal cancer patients undergoing preoperative radiotherapy. c Time from diagnosis to start of treatment for rectal cancer patients with surgery as the initial treatment
A

Time from diagnosis to surgery

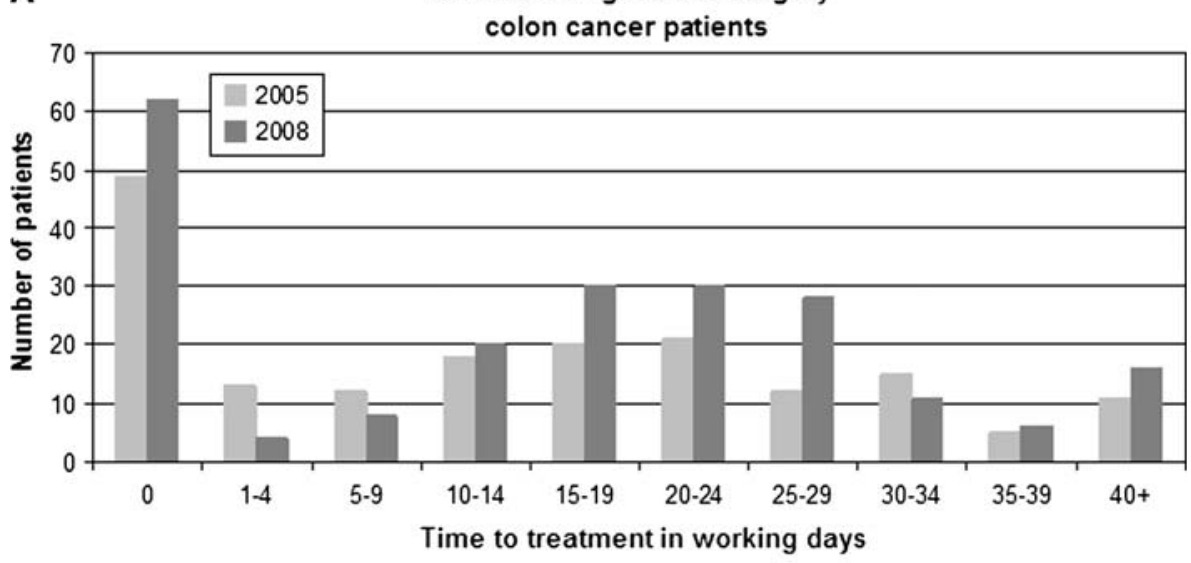

B

Time from diagnosis to radiotherapy rectal cancer patients

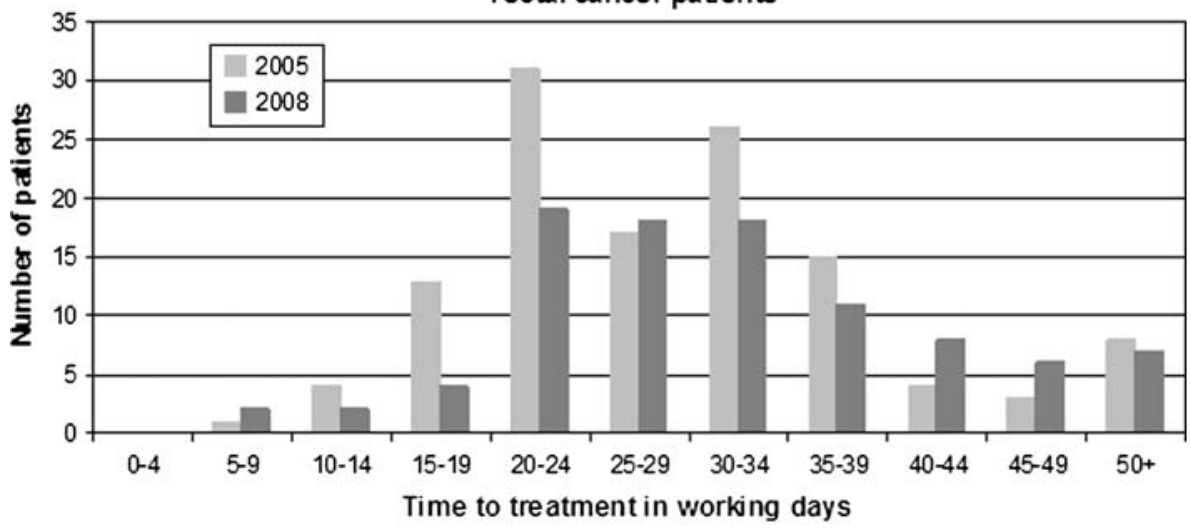

C

Time from diagnosis to surgery rectal cancer patients with surgery as initial treatment

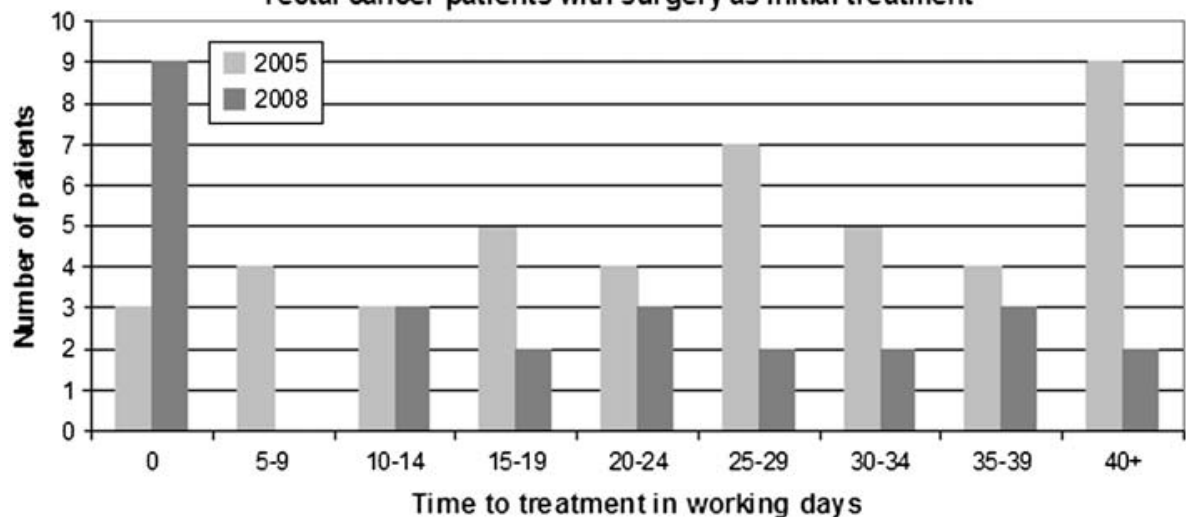

days in 2008 (Fig. 1a). Excluding those who underwent nonelective surgery in $2005(n=49)$, the median time to treatment was 20 working days. No differences were found in time to treatment between subgroups of colon cancer patients in 2005, except for hospital of diagnosis and stage of disease. The median time to treatment varied substantially among hospitals, ranging from 5 to 28 working days in 2005. Time to treatment decreased in 2005 with increasing stage, ranging from 21 working days for stage I to 4 working days for stage IV. In 2008 similar results were found, with a significantly longer time to treatment for patients with a co-morbidity. No differences in time to treatment were found for colon cancer patients between 2005 and 2008, except for one hospital where the time to treatment increased from 5 working days in 2005 to 16 working days in 2008 (Table 3).

For patients with rectal cancer, the median time to preoperative radiotherapy (mainly $5 \times 5 \mathrm{~Gy}$ ) was similar: 
Table 3 Time from diagnosis to first treatment (in working days): colon cancer patients

\begin{tabular}{|c|c|c|c|c|}
\hline \multirow[t]{2}{*}{ Parameter } & \multicolumn{2}{|c|}{2005} & \multicolumn{2}{|c|}{2008} \\
\hline & No. & $\begin{array}{l}\text { Median } \\
(5 \%-95 \% \\
\text { range) (days) }\end{array}$ & No. & $\begin{array}{l}\text { Median } \\
(5 \%-95 \% \\
\text { range) (days) }\end{array}$ \\
\hline Overall & 171 & $13(0-40)$ & 215 & $17(0-43)$ \\
\hline \multicolumn{5}{|l|}{ Age group } \\
\hline$<70$ years & 71 & $13(0-40)$ & 96 & $15(0-43)$ \\
\hline $70+$ years & 100 & $13(0-40)$ & 119 & $18(0-44)$ \\
\hline \multicolumn{5}{|l|}{ Stage } \\
\hline I & 26 & $21(9-40)$ & 39 & $21(0-44)$ \\
\hline II & 66 & $16(0-35)$ & 75 & $16(0-36)$ \\
\hline III & 51 & $12(1-37)$ & 72 & $18(0-34)$ \\
\hline IV & 27 & $4(0-32)$ & 22 & $9(0-30)$ \\
\hline Unknown & 1 & NA & 7 & NA \\
\hline \multicolumn{5}{|c|}{ Socioeconomic status } \\
\hline Low & 42 & $13(0-33)$ & 50 & $17(0-44)$ \\
\hline Intermediate & 59 & $12(0-55)$ & 82 & $21(0-43)$ \\
\hline High & 60 & $15(0-37)$ & 66 & $16(0-43)$ \\
\hline Institutionalized & 7 & $14(0-53)$ & 8 & $0(0-28)$ \\
\hline Unknown & 3 & NA & 9 & $18(0-49)$ \\
\hline \multicolumn{5}{|l|}{ Co-morbidity } \\
\hline 0 & 70 & $14(0--8)$ & 104 & $17(0-43)^{*}$ \\
\hline 1 & 51 & $13(0-40)$ & 48 & $17(0-32)$ \\
\hline$\geq 2$ & 39 & $12(0-40)$ & 54 & $19(0-48)$ \\
\hline Missing & 11 & $24(0-76)$ & 9 & NA \\
\hline \multicolumn{5}{|c|}{ Hospital stay (days) } \\
\hline 1 & 26 & $13(0-31)^{*}$ & 28 & $13(0-42)$ \\
\hline 2 & 28 & $12(0-28)$ & 46 & $17(0-34)$ \\
\hline 3 & 27 & $13(0-70)$ & 28 & $18(0-30)$ \\
\hline 4 & 37 & $28(0-55)$ & 37 & $20(0-66)$ \\
\hline 5 & 20 & $6(0-41)$ & 15 & $17(0-60)$ \\
\hline 6 & 33 & $5(0-27)$ & 61 & $16(0-43)^{* *}$ \\
\hline
\end{tabular}

$* p<0.05$ between hospitals in 2005; ** $p=0.02$ between 2005 and 2008

28 working days in 2005 and 30 working days in 2008 (Fig. 1b). In 2005 the time to surgery as initial treatment was 26 working days, whereas it in 2008 was 18 working days (Fig. 1c). No significant differences were found for subgroups of patients with rectal cancer who underwent preoperative radiotherapy in 2005 , but there was a significant difference between hospitals in 2008, ranging from 24 to 38 working days. Furthermore, a significant increase in time to treatment was found in one hospital. The number of patients with rectal cancer who did not undergo preoperative radiotherapy was small. However, a significant decrease in time to treatment was found between 2005 and 2008 for elderly patients ( $\geq 70$ years). Similarly, a reduced time to treatment for patients with stage I rectal cancer was found in 2008 compared to that in 2005. For patients with rectal cancer who underwent preoperative radiotherapy, the median time from diagnosis to registration at the radiotherapy institute was 17 working days (5\%-95\% range: 535 days); and the median time from registration to start of radiotherapy was 10 working days (5\%-95\% range: 418 days) in 2005 . The median time between start of preoperative radiotherapy and surgery was $7(5 \%-95 \%$ range: 5-67 days) in 2005. Similar time intervals were found for 2008. No significant difference was found in time to treatment between the two radiotherapy institutes, although the time to treatment differed by 7 working days between the two radiotherapy institutes in 2008 (Table 4).

In 2005, imaging procedures for diagnostic purposes of CRC largely consisted of thoracic radiography and abdominal US, which were usually conducted 6 to 8 working days after diagnosis. Abdominal and thoracic CT were used more often for CRC patients in 2008 than in 2005. The use of pelvic MRI increased from $39 \%$ in 2005 to $66 \%$ in 2008 for patients with rectal cancer (Table 5). The time from diagnosis to abdominal and/or thoracic CT was usually 7 working days for CRC patients in 2008, whereas abdominal US and thoracic radiography were usually conducted 4 working days after diagnosis in 2008 .

In patients with colon cancer, the time to treatment varied by the symptoms at diagnosis, being around 5 working days (5\%-95\% range: $0-35$ days) for patients with severe symptoms such as diarrhea, weight loss, and abdominal pain. Patients with symptoms clustered in the early-stage cluster had a time to treatment interval of 21 working days (5\%-95\% range: 0-38 days). A less clear pattern was found for rectal cancer (data not shown).

The time to treatment was less than 15 working days in $45 \%$ of colon cancer patients in 2008, whereas the corresponding figure was 53\% in 2005. Preoperative radiotherapy was given to $4 \%$ of rectal cancer patients within 15 working days in both 2005 and 2008. A significantly higher proportion of rectal cancer patients received initial surgery within 15 working days ( $23 \%$ vs. $46 \% ; p=0.04)$ (Table 6 ).

Survival analysis showed that a shorter waiting time was not associated with an improved outcome (data not shown). After adjusting for tumor stage, differentiation grade, age, co-morbidity, socioeconomic status, and sex in a multivariate proportional hazards regression analysis, this result did not change (data not shown).

\section{Discussion}

The Dutch Cancer Society working group (consisting of medical specialists, social medicine specialists, and an economist) proposed in 2005 that the interval between 
Table 4 Time from diagnosis to first treatment (in working days): rectal cancer patients

\begin{tabular}{|c|c|c|c|c|c|c|c|c|}
\hline \multirow[t]{3}{*}{ Parameter } & \multicolumn{4}{|c|}{2005} & \multicolumn{4}{|c|}{2008} \\
\hline & \multicolumn{2}{|c|}{ No preopRT } & \multicolumn{2}{|c|}{ PreopRT } & \multicolumn{2}{|c|}{ No preopRT } & \multicolumn{2}{|c|}{ PreopRT } \\
\hline & No. & $\begin{array}{l}\text { Median (5\%-95\% } \\
\text { range) (days) }\end{array}$ & No. & $\begin{array}{l}\text { Median (5\%-95\% } \\
\text { range) (days) }\end{array}$ & No. & $\begin{array}{l}\text { Median (5\%-95\% } \\
\text { range) (days) }\end{array}$ & No. & $\begin{array}{l}\text { Median (5\%-95\% } \\
\text { range) (days) }\end{array}$ \\
\hline Overall & 41 & $26(0-76)$ & 125 & $28(15-53)$ & 26 & $18(0-68)$ & 95 & $30(13-52)$ \\
\hline \multicolumn{9}{|l|}{ Age group } \\
\hline$<70$ years & 20 & $19(0-61)$ & 52 & $30(16-62)$ & 9 & $29(0-37)$ & 60 & $30(16-52)$ \\
\hline $70+$ years & 21 & $32(11-79)$ & 73 & $25(15-80)$ & 17 & $10(0-98)^{* *}$ & 35 & $29(16-59)$ \\
\hline \multicolumn{9}{|l|}{ Stage } \\
\hline I & 13 & $33(0-97)$ & 38 & $30(19-60)$ & 11 & $13(0-37)^{* *}$ & 23 & $32(19-52)$ \\
\hline II & 8 & $27(0-36)$ & 33 & $28(15-95)$ & 6 & $22(0-98)$ & 30 & $29(20-47)$ \\
\hline III & 13 & $24(0-76)$ & 29 & $24(13-43)$ & 9 & $19(0-68)$ & 25 & $28(16-47)$ \\
\hline IV & 7 & $15(5-26)$ & 21 & $31(14-61)$ & 0 & NA & 9 & $37(13-113)$ \\
\hline Unknown & 0 & NA & 4 & NA & 0 & NA & 8 & $29(8-46)$ \\
\hline \multicolumn{9}{|c|}{ Socioeconomic status } \\
\hline Low & 7 & $31(0-97)$ & 28 & $29(16-84)$ & 6 & NA & 21 & $28(16-59)$ \\
\hline Intermediate & 11 & $26(5-47)$ & 46 & $30(13-60)$ & 5 & & 41 & $32(20-47)$ \\
\hline High & 17 & $19(0-81)$ & 44 & $26(18-45)$ & 11 & & 31 & $28(19-45)$ \\
\hline Institutionalized & 5 & NA & 5 & NA & 2 & & 1 & NA \\
\hline Missing & 1 & NA & 0 & NA & 2 & & 0 & NA \\
\hline \multicolumn{9}{|l|}{ Co-morbidity } \\
\hline 0 & 25 & $25(0--1)$ & 62 & $28(16-47)$ & 12 & $13(0-98)$ & 52 & $30(16-50)$ \\
\hline 1 & 10 & $33(0-76)$ & 38 & $31(16-62)$ & 7 & $19(0-36)$ & 19 & $30(7-113)$ \\
\hline$\geq 2$ & 5 & NA & 17 & $27(14-84)$ & 7 & $28(0-68)$ & 20 & $32(20-69)$ \\
\hline Missing & 1 & NA & 8 & $29(13-220)$ & 0 & & 4 & NA \\
\hline \multicolumn{9}{|l|}{ Hospital stay (days) } \\
\hline 1 & 6 & $30(6-76)$ & 24 & $24(12-38)$ & 2 & NA & 17 & $24(11-44)^{*}$ \\
\hline 2 & 6 & $23(0-31)$ & 15 & $36(17-62)$ & 6 & & 15 & $30(7-113)$ \\
\hline 3 & 2 & NA & 30 & $29(15-60)$ & 5 & & 11 & $25(16-59)$ \\
\hline 4 & 1 & NA & 24 & $30(16-84)$ & 1 & & 14 & $29(8-42)$ \\
\hline 5 & 14 & $35(19-81)$ & 17 & $31(20-80)$ & 4 & & 11 & $28(20-52)$ \\
\hline 6 & 12 & $20(0-47)$ & 15 & $23(13-130)$ & 8 & & 27 & $38(24-79)^{* *}$ \\
\hline \multicolumn{9}{|c|}{ Radiotherapy institute } \\
\hline 1 & - & - & 45 & $30(17-53)$ & - & - & 51 & $32(20-52)$ \\
\hline 2 & - & - & 77 & $27(14-60)$ & - & - & 44 & $25(13-52)$ \\
\hline
\end{tabular}

$* p<0.05$ between hospitals in 2008 ; ** $p<0.05$ between 2005 and 2008

Table 5 Percentages of CT and MRI diagnostic imaging in colon and rectal cancer patients

\begin{tabular}{lll}
\hline Parameter & $2005(\%)$ & $2008(\%)$ \\
\hline Colon & & \\
Abdominal CT & 49 & 68 \\
Thoracic CT & 14 & 26 \\
Rectum & & \\
Abdominal CT & 61 & 75 \\
Thoracic CT & 20 & 46 \\
Pelvic MRI & 39 & 66 \\
\hline
\end{tabular}

Table 6 Percentage of patients in whom treatment was started in time according to Dutch Cancer Society advice ( $<15$ working days)

\begin{tabular}{lll}
\hline Patient conditions & $2005(\%)$ & $2008(\%)$ \\
\hline Colon cancer & 53 & 45 \\
$\begin{array}{l}\text { Rectal cancer without preoperative } \\
\text { radiotherapy }\end{array}$ & 23 & $46^{*}$ \\
$\begin{array}{l}\text { Rectal cancer with preoperative } \\
\text { radiotherapy }\end{array}$ & 4 & 4 \\
$* p<0.05$ & & \\
\hline$* p$ &
\end{tabular}


diagnosis and treatment of cancer should be less than 15 working days [5]. Based on our results from 2008, we can conclude that this advice seems far from feasible to adhere to in the southern Netherlands; $45 \%$ of colon cancer patients, $46 \%$ of rectal cancer patients with surgery as their initial treatment, and only $4 \%$ of patients with rectal cancer who underwent preoperative radiotherapy were treated within 15 working days in 2008. No shortening of the interval from diagnosis to treatment was seen between 2005 and 2008. Moreover, there was substantial variation in time to treatment among hospitals.

Little is published about time to treatment of CRC patients after diagnosis. However, in Denmark the median time interval from diagnosis to treatment was 9 days for colon cancer patients and 15 days for rectal cancer patients [6]. The Danish fast-track recommendations, introduced in 1998, stated that the time interval between diagnosis and treatment should be less than 14 days. In a large population-based study of CRC patients diagnosed during 20012002 , these recommendations were poorly met; $79 \%$ of the colon cancer patients and $47 \%$ of rectal cancer patients started treatment within 14 days after diagnosis [6]. The UK government decided that from July 2000 all patients suspected by their general practitioner to have bowel cancer should be seen by a specialist within 2 weeks of the date of referral [18]. Although cancer patients referred to a 2-week standard clinic were seen more quickly, it did not reduce the overall time to treatment or stage of disease at surgery [19]. It is a good initiative to diagnose patients quickly, but it should be expanded to treatment to reduce the interval from diagnosis to start of treatment.

Although in recent years much attention has been paid to reducing the time to treatment in hospitals in The Netherlands, a shortening in time to treatment between 2005 and 2008 could not be observed. To decrease the interval between diagnosis and treatment, a project called Sneller Beter (Getting Well Faster) was started in November 2003 in The Netherlands funded by the Ministry of Health [8]. One of the results of this project was a reduction of 30 days (from 69 to 39 days) between first visit to the hospital and start of treatment, usually due to more efficient process reorganization [20]. In October 2004 two hospitals included in our study engaged in this project, which indeed resulted in quicker start of surgical treatment of colon cancer patients in 2005 compared to other hospitals in southern Netherlands. However, the advantage of these two hospitals had diminished in 2008 . Another initiative to reduce time to treatment for CRC patients was the advice by the Dutch Cancer Society working group, which proposed in 2005 that all patients with cancer be treated within 15 working days. Therefore, we expected a decrease in time to treatment between 2005 and 2008. A possible explanation for the lack of improvement is the increased incidence of CRC and the probably more severe and complicated co-morbidities of the patients, which need to be managed before treatment can be started.

Imaging procedures for diagnostic assessment changed from largely abdominal US and thoracic radiography in 2005 to abdominal CT and thoracic radiography or thoracic CT in 2008. In addition, pelvic MRI was indicated for patients with rectal cancer in 2008. However, the results of our study indicate that it is unlikely that these changes are responsible for the lack of reduction in time to treatment; moreover, the waiting time for a CT scan was similar to the waiting time for abdominal US and thoracic radiography in 2005.

Most patients with CRC diagnosed in 2005 or 2008 in southern Netherlands, especially those with rectal cancer, did not receive treatment within 15 working days. This can be attributed mainly to hospital factors, including logistics and multidisciplinary consultation. There are no quantitative data about the influence of delay on prognosis in the literature. The interpretation of different studies regarding the association between delay and prognosis is hampered by factors such as tumor stage and differentiation as well as patient priority [9]. Therefore, it is controversial to what degree the time to treatment contributes to stage of disease and therefore prognosis [9].

We did not find a positive association between a short time interval from diagnosis to treatment and survival. Therefore, it can be assumed that other factors not addressed in this analysis-such as priority of a patient for start of treatment-are more important for survival than time to treatment. However, this does not mean that time to treatment is not important for the patients. CRC is a lifethreatening disease, and a long time interval from diagnosis to treatment might cause enormous stress for cancer patients. Such stress can result in deterioration of the patient's health, condition, and well-being [10,11], which may affect his or her physical condition, in turn resulting in more complications and a longer hospital stay. Therefore, reducing time to treatment can reduce health care costs. Furthermore, patients are generally more satisfied when they are treated soon after being diagnosed, which results in a better working environment for health care workers and increases the quality of the overall health care system. In addition, based on tumor biology it is important to keep time to treatment as short as possible. It can be assumed that in a large proportion of patients a long time to treatment results in deterioration of the prognosis. Therefore, the time from diagnosis to treatment should be minimized.

It seems far from feasible to follow exactly the current advice of the Dutch Cancer Society in most of our CRC patients. Therefore, we propose new advice based on the general guidelines for time to treatment in Dutch 
specialized care and the results of this study. Guidelines in Dutch specialized care reveal a time to treatment from diagnosis to start of clinical treatment within 35 days for $80 \%$ of patients and within 49 days for all patients [4]. Cancer patients, however, suffer from a life-threatening disease and should definitely be treated within this time. Moreover, they experience a lot of stress and uncertainty during the time to treatment. Therefore, we propose that the time from diagnosis to start of treatment should be an interval of less than 20 working days. According to this rule, $58 \%$ of colon cancer patients, $50 \%$ of rectal cancer patients with surgery as their initial treatment, and $9 \%$ of rectal cancer patients who will undergo preoperative radiotherapy can meet the advised conditions.

Based on our results, there seems to be no reduction in time to treatment for patients with CRC in southern Netherlands between 2005 and 2008. Attention and effort should be paid to reducing time to treatment, which is especially valuable in view of the increasing proportion of patients with CRC due to the aging population and the introduction of population mass screening for CRC in the near future.

Acknowledgments The authors thank the registration team of the Eindhoven Cancer Registry for their dedicated data collection. This study was carried out with a grant from the Dutch Cancer Society (IKZ 2006-3588).

Open Access This article is distributed under the terms of the Creative Commons Attribution Noncommercial License which permits any noncommercial use, distribution, and reproduction in any medium, provided the original author(s) and source are credited.

\section{References}

1. www.ikcnet.nl/. Accessed 18 Nov 2009

2. Martijn H, Voogd AC, van de Poll-Franse LV et al (2003) Improved survival of patients with rectal cancer since 1980: a population-based study. Eur J Cancer 39:2073-2079

3. Lemmens VEPP, van Steenbergen LN, Janssen-Heijnen MLG et al. (2010) Trends in colorectal cancer in the south of The Netherlands 1975-2007. Acta Oncol (in press)
4. www.treeknormen.nl/. Accessed 16 March 2009

5. Signaleringscommissie Kanker (2005) Advies inzake wachttijdnormen in de kankerzorg. KWF Kankerbestrijding

6. Korsgaard M, Pedersen L, Laurberg S (2008) Delay of diagnosis and treatment of colorectal cancer: a population-based Danish study. Cancer Detect Prev 32:45-51

7. Department of Health (2000) Referral guidelines for suspected cancer. Department of Health, London, UK

8. www.snellerbeter.nl/. Accessed 8 Sept 2009

9. Ramos M, Esteva M, Cabeza E et al (2008) Lack of association between diagnostic and therapeutic delay and stage of colorectal cancer. Eur J Cancer 44:510-521

10. Risberg T, Sorbye SW, Norum J et al (1996) Diagnostic delay causes more psychological distress in female than in male cancer patients. Anticancer Res 16:995-999

11. Schag CA, Ganz PA, Polinsky ML et al (1993) Characteristics of women at risk for psychosocial distress in the year after breast cancer. J Clin Oncol 11:783-793

12. Stapley S, Peters TJ, Sharp D et al (2006) The mortality of colorectal cancer in relation to the initial symptom at presentation to primary care and to the duration of symptoms: a cohort study using medical records. Br J Cancer 95:1321-1325

13. Janssen-Heijnen MLG, Louwman WJ, van de Poll-Franse LV et al (2005) Results of 50 years cancer registry in the south of The Netherlands: 1955-2004. Eindhoven Cancer Registry, Eindhoven (in Dutch)

14. Janssen-Heijnen ML, Houterman S, Lemmens VE et al (2005) Prognostic impact of increasing age and co-morbidity in cancer patients: a population-based approach. Crit Rev Oncol Hematol 55:231-240

15. Van Duijn C, Keij I (2002) Sociaal-economische status indicator op postcode niveau. Maandstatistiek van de Bevolking 50:32-35

16. Schouten LJ, Hoppener P, van den Brandt PA et al (1993) Completeness of cancer registration in Limburg, The Netherlands. Int J Epidemiol 22:369-376

17. Fritz A, Percy C, Jack A et al (2000) International classification of diseases for oncology, 3rd edn. World Health Organisation, Geneva

18. Executive NHS (1997) The new NHS-modern. Dependable. Department of Health, London, UK

19. Flashman K, O'Leary DP, Senapati A et al (2004) The Department of Health's "two week standard" for bowel cancer: is it working? Gut 53:387-391

20. EL NIV (2008) Evaluatie Sneller Beter pijler 3: Resultaten van een verbeterprogramma voor ziekenhuizen. NIVEL, Utrecht 